\title{
Suggestion on Chinese High Education Reform Based on the Comparison of Education Philosophy Between China and America
}

\author{
Huijie Wang ${ }^{1, *}$ \\ ${ }^{1}$ School of No.1 Middle School, 261031, Weifang City, Shandong Province, China \\ "Corresponding author. Email: HuijieOliviaWangCWSS@cseec.education
}

\begin{abstract}
High school education serves as a bridge between compulsory and higher education. High school education reflects the quality of national education and affects a country's overall economic strength and educational progress. As the campus environment is covered by exam-orientation, the utilitarianism and instrumentalization of educational contents, the goal of education deviates that Chinese students' creativity, cooperation and communication ability have not been well developed. This article aims to make a comparison between the US and China in terms of educational philosophy. It embodies the ideal values and pursuit of education and is enriched as people's growing understanding of educational development. It contains four areas (i.e., educational purpose, subject development, classroom discipline, and competition and cooperation). The findings showed that the purpose of education in China is to develop the test-taking ability, while the educational goal in the US is to cultivate qualified citizens. Besides, China's discipline development is biased towards scientism, while the US adopts multiple intelligence theory. Third, China classroom discipline emphasizes teachers' authority and honor the truth, while freedom and equality are valued in the US.
\end{abstract}

Keywords: Education Philosophy; Comparison Education; Chinese High Education Reform; Sino-America Senior High schools.

\section{INTRODUCTION}

High school education is such an important stage that it can determine a person's future path. On the one hand, a high school diploma is widely considered the minimum requirement for employment. On the other hand, students in high school represent the country's future and hope. Whether or not students can receive qualified education is directly connected to the country's and region's growth and the issue of international competitiveness.

The high education system has been reformed since 1985 and achieved remarkable success. China has achieved a new level of universal access to education. In 2019, the completion rate of nine-year compulsory education reached 94.8 percent, the gross enrollment rate of senior high school education reached 89.5 percent, and the gross enrollment rate of higher education reached 51.6 percent [1]. Furthermore, 24,400 high school education schools nationwide in 2019 increased 55 over the previous year, with 14.396 million students enrolled. An increase of 901,100 people over the previous year, an increase of $6.66 \%$ [2].

Even though China's high school education has progressed to a level of mass development, the pressure for further studies in secondary school education remains high. Chinese students face mounting pressure when they first step into campus. The Ministry of Education in China reported that the number of students who attended the 2019 National College Entrance Examination (NCEE) is 10.31 million, with 4.31 million undergraduate students admitted, representing a 41.8 percent undergraduate admission rate [3]. Due to many participants in the entrance exam, the admission rate is less than half, meaning that competition is high. Almost all secondary school students attend tutorial classes at the expense of the weekend, largely extending the time spent on study. 


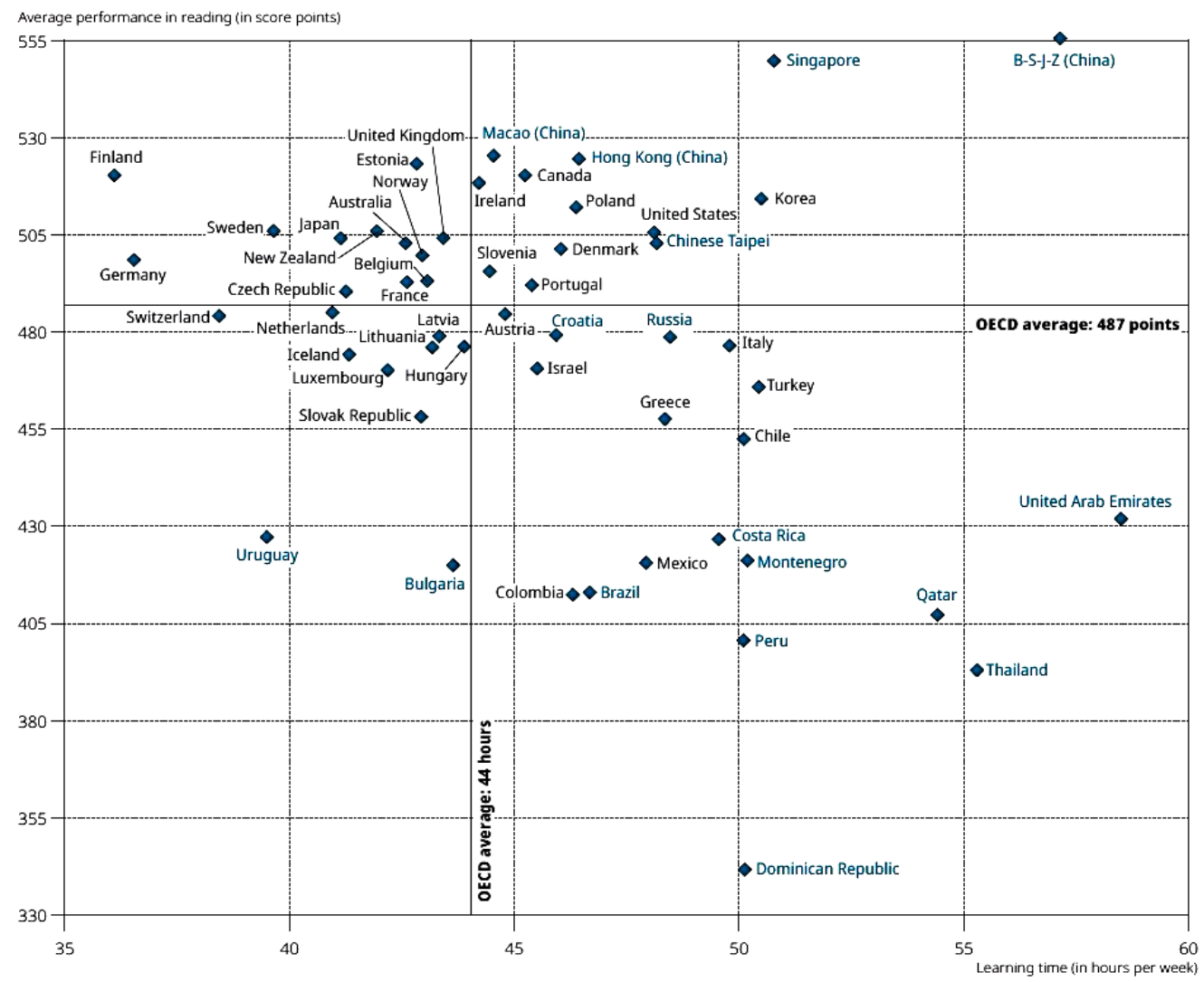

Figure 1: Reading performance and total learning time per week, sourced from PISA 2018 Database

In order to test the academic performance of 15-yearold students from member and non-member countries, OECD (2018) assesses the academic performance in Reading, Math, and Science every three years. The result of 600,000 15-year-old children from 79 countries and territories showed that China bags first place in all categories. Despite its excellent academic performance, students spend the longest time studying, reaching 57 hours, while the OECD average is only 44 hours. However, Finland's total score and single tests are in the top ten, but Finnish students had the least reading time per week, at 36 hours, compared to 21 hours more in China [4].

In contrast, the United States, as an education powerhouse, establishes many advanced education concepts Academic achievement, for example, is not the only criterion for admission to Ivy League; students' skills and leadership abilities are also essential elements in their acceptance. As a result, to gain admission to the university of their choice, students must actively participate in a variety of competitions and social activities, as well as receive training and development in a variety of strengths to improve their competitiveness when applying to universities. Moreover, the manifestation in American education is the tendency of pragmatism in which education serves production and concentrates on building theoretical and technical abilities. The basic tenets of American education can be seen from the curriculum of American high schools: visual art courses, performance art courses, vocational courses. This is done to cultivate students' interests and let them know their strengths and preferences. Instead of using scores as the assessment criteria, American educators establish correct values and cultivate students' personalities.

Chinese indeed learn from America and achieve progress. In addition to learning language, mathematics, and other disciplines, Chinese education integrates more elements of quality education, encouraging students to engage in more social practices and learn more beyond the content of textbooks. In China's Shandong province, for example, The comprehensive quality evaluation objectively reflects the systematic evaluation of the overall development of students' morality, intelligence, physical beauty, and is conducive to promoting students' self-understanding, self-improvement, and proactive development; promoting the reform of evaluation methods and changing the practice of evaluating students based on test scores as the sole criterion. To provide an important reference for the admissions of colleges and universities, which has been warmly appreciated [5].

However, the changes' outcomes are far from satisfactory because of The low localization performance 
that fails to embrace individualized and diverse education. The research topics of domestic and foreign scholars are more about the research on the reform of the national or regional high school education system, diversity of high school education development. The study of school running mode, and the international comparative study of educational development. But there is a lack of research on making recommendations for China's education reform through comparison. Therefore, this paper tries to compare education philosophy between China and American states and give some suggestions on Chines High Education Reform.

\section{EDUCATIONAL PHILOSOPHY}

Educational philosophy reflects the value orientation and ideal pursuit of education, including educational purposes, subject development, and class discipline.

Since the founding of New China, educational philosophy has played an indispensable role in constructing educational values and spiritual cohesion in the process of China's educational development. Traditional Chinese culture highlights morality and ethics and promotes moral rules and standards, which accumulated into a unique Chinese traditional education philosophy.

The educational purpose is test-oriented, meaning that the whole education system improves test scores [6]. Under the baton of the college entrance examination, all teaching content must serve the college entrance examination requirement. In addition, the uniform test design and standard answers make students only pay attention to the books and even only remember the contents of the books. Secondly, to apply modern science and technology to production, it is essential to enable the younger generation to master modern science and culture [7]. Therefore, to implement the strategy of rejuvenating the country through science and education in the new era, China emphasizes natural science disciplines such as physics, chemistry, biology. Influenced by the traditional imperial examination system, Chinese students are fully aware of the competitiveness in society the moment after they get into primary schools [8]. By way of explanation, students are accustomed to competitions and peer comparisons based on grades and qualifications.

Class discipline is a series of codes of conduct in the classroom, which reflects the relationship between teachers and students in the classroom. It is targeted to play a positive role in the students' development, rational, humane and should be obeyed by the whole students [9]. It ensures the smooth running of teaching and learning activities and has positive significance in stabilizing students' emotions and strengthening their self-control of behavior, promoting their socialization and the formation of good personality qualities. Due to the influence of
Confucius's philosophy, the basic norm that every Chinese should follow is 'respect for teachers.

\subsection{Education Purposes}

Grades are the primary measure for assessing a student's qualities in China's present education system and the selection criteria for the National College Entrance Examinations. Academic qualifications, rather than aptitude, are valued in the social recruiting system. Due to the scarcity of quality university education resources, China's National College Entrance Examinations can be said to be an army of thousands of men trying to cross a single-log bridge. In this contest, China has given rise to a slew of "college entrance test factories" aimed at improving results, with Middle School of Anhui Lu'an holding the distinction of Asia's largest "college entrance exam factory", and there are no internet cafes, no playgrounds and no places of entertainment in the town. As China's basic education has always revolved around the National College Entrance Examinations, focusing on the mastery of knowledge and response to the exams, the ability to sit the exams has become an overriding priority. Chinese teachers normally use the code model of communication in their teaching methods. The Chinese teachers want students to repeat what they said, literally trying to optimize the message's encoding, decoding, reproduction, and reproducibility.

Furthermore, Chinese classroom teaching is a typical teacher-based teaching approach in which the teacher instructs and monitors students authoritatively and seriously from the podium. Lecture, practice, and examination are the key to ensure that students receive excellent grades. However, it causes pupils to become too reliant on their teachers and textbooks, preventing them from asking novel and innovative questions.

The American philosophy of education is designed to prepare students to become competent or good citizens of society, civic education. This is mainly due to the American educator Dewey and the British educator John Henry Newman. The American pragmatist Dewey advocated the ideas of 'education as life', 'school as society', and 'the goal of education is the development of competent citizens' [10]. Dewey's educational philosophy is distinguished by the fact that it begins with students' psychological characteristics and instincts to enable them to successfully integrate into society and thus become competent citizens in the future, and that education is merely a bridge or a ferry from this starting point to this end [11]. Dewey advocated that the primary responsibility of schools lies in the cultivation of the humanistic aspects of students rather than in the accumulation of knowledge.

In the United States, humanism is essentially a spirit of freedom, independence and criticism, the ability to 
judge right from wrong, appreciation of teamwork, and even the harmony between man and nature. As a result, the United States places greater emphasis on fostering a spirit of innovation and self-discovery among students. In Bruner's book The Process of Education (1960), the main premise was that students are active learners who construct their knowledge. Education should aim to create autonomous learners who have not imparted knowledge but are self-driven [12].

Education in the US is primarily practical for students, focusing on character development and promoting application skills. Taking math as an example, in Chinese education, basic calculation skills are crucial to remember an entire concept. Chinese students are not permitted to use calculators from elementary school to high school. Chinese education emphasizes strictness and clarity, which helps students retain information. Students' self-assurance, self-determination, and independence are emphasized in American education, which aids in comprehensive thinking. Most of the Chinese believe that Americans' math is not the best.

Another commonly accepted view of education in the United States is to respect differences, to identify the characteristics and strengths of each student to the greatest extent possible, to provide them with targeted education, to improve the self-confidence of students continuously, and to give each child the opportunity to excel in life. Ms. Jie Zhang, Principal of Stevenson School in New York, says that the fundamental qualities of a person are not measured by grades but by the extent to which we can help our students to illuminate their dreams and embolden them for the future. Educational thinking in America emphasizes the ability of students to think independently so that students dare to be creative rather than blindly believe in authority. Teachers encourage pupils to share their own opinions and methods at all times during class. Instructors encourage students' autonomous and individual thinking and prevent them from providing the "one correct answer" to many issues regarding politics, religion, history, geography, and literature, promoting a diversity of viewpoints and refusing to enable teachers to substitute students thinking. The focus of tests is not on analytical skills but the reasonableness of the answers themselves.

\subsection{Subject Development}

In order to catch up with the United Kingdom and the United States as soon as possible, China placed great emphasis on scientific disciplines such as physics, chemistry and biology, and the whole society's belief in science and desire for material things reached an unparalleled level, giving rise to a "scientism" that overrode all religions. Scientism, defined by Kwok, places all reality within a natural order and deems all aspects of this order, be they biological, social, physical, or psychological, to be knowable only by the methods of science [13]. This strategy has resulted in a quick expansion of higher education and economic progress in China, increasing social conflicts.

Corresponding to this is the theory of multiple intelligences in the United States. First proposed by Harvard University cognitive psychologist Professor Howard Gardner in 1983 and published in his book Frames of Mind: The Theory of Multiple Intelligences. The theory of multiple intelligences suggests that the human brain has more than just one dimension of intelligence. Over the years, he and his team have refined this theory to include nine different types of human intelligence: musical, bodily-Kinesthetic, logicalmathematical, linguistic, spatial interpersonal, intrapersonal, and naturalist intelligence [14]. Gardner's multiple intelligences theory defies traditional intelligence theory's assumptions and provides strong theoretical support for curriculum and student evaluation in American high schools.

In terms of curriculum, a wide range of resources and a variety of courses and classes to fulfill their requirements in terms of professions, further education, and interests. American schools emphasize students' growth beyond academic performance, incorporating the study and application of the arts and technology into the school curriculum and providing students with excellent hardware to help them develop their multiple intelligences. They usually have an auditorium for drama practice, a fantastic concert hall and facilities for developing students' musical talents, an intriguing art lab where students can make a variety of crafts, students produce their TV shows, hold various art competitions, and the school corridors are brimming with student work. Multiple intelligences theory emphasizes that student assessment should not be simply dependent on academic success in cultural topics. Instead, it should evaluate many elements of pupils' intelligence from a variety of viewpoints and a holistic and developmental one.

\subsection{Classroom Discipline}

Coercive punishment is an effective means to manage their students in China. In 2011, the Guangming Daily published an article titled The Battle Hymn of the Tiger Mother in which Yale University professor Meier Tsai discussed three "successful experiences" she had in teaching her daughter. First, ignoring children's selfesteem. The second is believing that children must be filial to their parents. The third is believing that children are not able to discern [15]. The outstanding performance of the two daughters under the "tough mother" style of upbringing constituted an outrageous challenge to the democracy and benevolence concepts of the American parents.

In terms of classroom discipline, Confucian philosophy has had a profound impact on Chinese 
society. Most conspicuously, 'full respect for teachers' is mentioned. The Chinese Ministry of Education established the rule that students should strictly observe the discipline in class, including obeying teachers and sitting upright in class, Keeping quiet, not talking, not leaving their seats without permission [16]. Since Chinese teachers are fully aware of their responsibilities, they strive to help students achieve their goals as much as possible. Many teachers in China also still believe that "strict teachers make good students". Strict management may help students acquire information and test-taking abilities, but it is not helpful to the growth of students' enthusiasm in studying or self-confidence, and condemnation and criticism will only add to their inferiority feeling.

In American schools, the development of student's self-esteem and self-confidence is a priority. In the classroom, criticism is rarely heard. Even if some students are misbehaving or unable to respond to the teacher's questions, the teacher and the classroom environment encourage them. Students are free to express themselves, discuss, and even dispute in class at any moment. They believe that confidence and creativity are sometimes more important than knowledge. The instructor in the classroom does not focus on explanations but rather assists the students in discussing certain themes, and the students are the main characters in the lesson. The instruction stresses teacher-student contact and encourages students to voice their ideas, ask questions, and actively engage in information acquisition. Teachers and students in American schools are frequently observed debating over a topic, and they do not ask for the sole conventional response, instead of encouraging pupils to express differing viewpoints. Teachers and students engage with one another and learn from one another. However, many American students with low self-cognition and self-control capacities may quickly become mediocre and perplexed under this paradigm. Teachers and students are both subjects of the classroom in the American high school, and teachers respect students' autonomous learning based on their interests and needs. Teachers and students engage politely and democratically with one another, with the difference between master and subordinate being removed, making teachers and students more like free and equal friends. Carl Ransom Rogers, one of the most famous contemporary American humanistic psychologists and educational reformers, founded the "non-directive teaching" theory, which differs from the Chinese theory of 'fully respect to teacher'. He proposed the idea of student-centered "non-directive" teaching [17]. He put the student in the highest position and believed that all teaching should promote students' self-fulfillment. He believes that teachers are people who facilitate learning. In this way, teachers are no longer the central figure in teaching, and they cannot organize, instruct and evaluate. He only participates in student activities as an ordinary class member, with a sincere attitude. Students get along on an equal footing and exchange thoughts and feelings with each other.

\subsection{Competition and Cooperation}

The significance of 'competition' in the Chinese education system can be traced back to the traditional Chinese imperial examination system [18]. One of the primary methods for selecting or eliminating individuals is to compare and rate their performance. As a result, being a better version of yourself is insufficient. In order to attain one's goal, one needs to outperform one's peers in all of the exams. Because of the traditional imperial examination system, the Darwinian evolutionary theory of "survival of the fittest", and the relative lack of resources per capita, China attaches great importance to developing students' "competitive consciousness" in both patenting education and school education. Chinese parents convey to their children as early as preschool that they are expected to excel in school, a very competitive atmosphere. Students compare themselves with others in their studies, teachers compare themselves with other teachers in their subjects, and Chinese teachers often encourage students to be competitive in their ideological work. The idea of competition does play a positive role in developing students' motivation and perseverance in learning; however, it also makes Chinese people conservative and difficult to cooperate with others.

Secondly, Chinese people regard learning as a door knocker, and the purpose of education is to change their own and their family's fate, get ahead, be better than others, and climb up to a higher status. This is what parents expect of their children, and this is what students expect of themselves. And the poorer families they come from, the stronger such aspirations become. Therefore, in the process of receiving education, students seldom value their own feelings but attach great importance to the feelings of others looking at them, and students have to be the first in their class, school and even city and province, and to be the second is an intolerable failure. The Chinese families finish their children's education in the process of struggling to achieve such goals one after another.

Cooperation and teamwork are appreciated in today's culture in all sectors of life. American culture is collaboration, and the notion of cooperation and sharing pervades all aspects of American high school education [19]. Many teachers like to organize students into learning teams, assign a job to them, split the work among the teams, with each team member responsible for a piece of the work, and then give the team members a score depending on how effectively the team accomplished the assignment as a whole. Everyone receives good scores if they finish well. Everyone must work together in this instance. Students may learn how to express themselves, accept others' ideas, and learn from 
them via this collaboration. Students may learn how to voice their ideas, respect and learn from others' opinions, recognize the significance of a cooperative attitude, and collaborate with others via this collaboration. Unlike Chinese students' expectations of future success, Americans are taught to find what they enjoy doing, discover themselves, and become the person they are ultimately supposed to be. The purpose of life and education is to discover and actualize these ideals. As a result, they place a high value on feeling self-conscious and comparing themselves to themselves and whether they are more improved today than yesterday. In American schools, especially in kindergarten and elementary schools, the schools never allow students and parents to compare themselves; each child is the best one in an individual sense. This is an important reason for the strong self-confidence of American students and even of Americans in general.

\section{CONCLUSION}

The purpose of this article is to compare educational philosophy differences between Chinese and American high school education from four perspectives and then to give some suggestions and recommendations for reforming high school education in China.

The findings showed that Chinese teachers focus more on textbook knowledge and try to explain each topic from multiple perspectives, but they neglect the practical application of knowledge and cultivate students' creative thinking. American teachers, on the contrary, focus more on students' exploration and let them solve many problems on their own without answering a specific problem from a single perspective.

In China, the sense of competition positively affects students' motivation and drive, but it also makes Chinese students conservative, reluctant to work with others and under great pressure. In contrast, the classroom atmosphere in the United States places more importance on developing students' self-esteem and self-confidence, and students can freely express their opinions, but such a classroom atmosphere is not conducive to the development of students with poor self-control.

In general, Chinese education does not sufficiently emphasize nurturing problem-solvers or innovators. Chinese students do not receive proper training that can cultivate their critical thinking and problem-solving ability. Consequently, it is not easy for them to objectively understand, analyze, and evaluate an issue or idea. The lessons from the US provide strong implications for the reform of Chinese high schools. The current shortcomings of high school education in China include examinations are too frequent, and teachers are convinced of rote learning, which makes learning too laborious for students as they need to spend too much time on it. Consequently, the learning effect is not very obvious.

To solve this issue, China should reevaluate the examination and assessment methods and change the concept that one's fate is determined merely by the university entrance examination. Secondly, scores should not be the only criterion to judge students' ability, and several other factors should also be considered in university admission. Chinese high schools should increase the proportion of practical sessions in their training programs and allow students to participate in more internship practices, especially social practices, to make students more adaptable to society. Thirdly, schools should provide diversified courses for students, reducing the proportion of compulsory courses and teaching time to a normal level. Schools are encouraged to attend special courses to make the curriculum more diversified so that students can freely choose the courses they are interested in, promoting the development of students' personalities. Fourthly, teachers should advocate heuristic teaching methods to promote student's self-motivation. For instance, teachers can use multimedia technology and information network resources to enrich teaching methods. Teachers should cultivate students' ability to identify problems and express their opinions; give students more hands-on opportunities, such as letting them take the initiative to collect information and find solutions, which can help students better absorb knowledge and cultivate their spirit of inquiry and innovation. Finally, Chinese high schools should promote substantial cooperation with foreign high schools in the context of globalization. Chinese high schools can send students to study and exchange with top foreign high schools by conducting joint training and short-term study tours. They can also establish friendly relations with top foreign high schools, allowing some outstanding students to exchange schools for study, which is conducive to the exchange of culture, thinking and behaviors between the two sides, and it can also help broaden students' horizons and minds.

\section{REFERENCES}

[1] Ministry of Education of the People's Republic of China. (2020, December 1). China's educational attainment at all levels is at or above the average of middle- and high-income countries.

[2] Ministry of Education of the People's Republic of China. (2021, August 27). Statistical Communiqué on National Education Development in 2020.

[3] 2019 college entrance examination admission rate announced: 6 million candidates missed the undergraduate course, is college entrance examination really getting harder and harder? (2019, August 7). Retrieved from https://www.sohu.com/a/332117090_100262507. 
[4] 2018 database - pisa. OECD. (n.d.). Retrieved from https://www.oecd.org/pisa/data/2018database/

[5] Shandong Education and research Network. (2016, August 12). Shandong Province general high school students comprehensive quality evaluation implementation measures. Retrieved from http://www.sdgov.org.cn/zynlksview-76.html.

[6] J.X. Lu, \& J.F.Tang,\& X.F. TANG, (2007). Journal of Hubei University of Economics. An Analysis of the Examination- Oriented Education System of China, 5.

[7] Guang-Wei, Z. (1985). China's educational aim and theory. International Review of Education, 31(1).

[8] Y.R. Zhao. (2015). Review on 'BBC Are our kids tough enough: Chinese Schools' based on history, literature and personal experience.

[9] Wang, H. (2011). Reflection and Reconstruction of Class Discipline in High Schools. College of Education Central China Normal University .

[10] G.J. Zhang. (2005). An Analysis of American Educational Ideas_-Notes on Investigation in the US Journal of Educational Science of Hunan $\mathrm{N}$ Ormal University, 4(3).

[11] Dewey. (1999). Dewey's lectures in china. Anhui Education Press. P.99.

[12] Bruner, J. S. (1961). Harvard educational review. The Act of Discovery, 31, 21-32.

[13] Uberoi, P. (1968). Chinese Conversion To Scientism. China Report, 4(2), 33-35. Published by the Yale University Press, New Haven (USA),

[14] Gardner, H. E. (2008). Multiple intelligences: New horizons in theory and practice. Basic books.

[15] Guangming Daily. (2011, February 15). "Battle Hymn of Tiger Mother" Raised American Educational Ideas.

[16] Ministry of Education of the People's Republic of China. (2015, August 25). Notice of the Ministry of Education on Issuing the "Code for Primary and Secondary School Students (Revised in 2015)".

[17] BG Ma. (2008). An Analysis of the Differences in the Characteristics of the Relationship between Teachers and Students in China and America.

[18] Berkshire Publishing Group, 2009. Civil Service Examinations .

[19] Z.H. Huang. (2005). Reflection and Reference on the Humanistic Spirit of American Universities. Chinese Higher Education, (20). 